Article

\title{
Molecular Diversity of The Tidal Swamp Rice (Oryza sativa L.) Germplasm of The South Kalimantan, Indonesia
}

\author{
Dindin H. Mursyidin 1, 2, Purnomo Purnomo ${ }^{2}$, Issirep Sumardi ${ }^{2}$ and Budi S. Daryono 2,* \\ 1 Faculty of Mathematics and Natural Sciences, Universitas Lambung Mangkurat, South Kalimantan, \\ Indonesia 70714; dindinhm@gmail.com \\ 2 Faculty of Biology, Universitas Gadjah Mada, Yogyakarta, Indonesia 55281; nomo@ugm.ac.id; \\ issirep@ugm.ac.id \\ * Correspondence: bs_daryono@mail.ugm.ac.id
}

\begin{abstract}
Tidal swamp rice has long been cultivated by the local people of the South Kalimantan, Indonesia. This germplasm possess some important traits for adapted to a wide range of abiotic and biotic stresses. In this study, a total of sixteen cultivars of this germplasm, consisting of fifteen of the South Kalimantan Province and one of Sumatera Island, Indonesia (an outgroup) were analyzed, phylogenetically based on the chloroplast $\operatorname{trn} \mathrm{L}-\mathrm{F}$ and nuclear intergenic spacer region (IGS). The results showed that this germplasm has a relatively more extraordinary genetic diversity than other local rice germplasm. In a nucleotide level, this germplasm showed a genetic diversity of 0.61 for nuclear IGS and 0.58 for $\operatorname{trn} \mathrm{L}-\mathrm{F}$. The phylogenetic reconstruction also exhibited that this germplasm has the unique illustration of phylogenetic trees, particularly for the combined sequence datasets. Thus, the results of our study would provide useful information for further understanding of evolutionary relationships of this germplasm and facilitate the efficient utilization of valuable genes for genetic improvement, particularly in the tidal swamp areas.
\end{abstract}

Keywords: Oryza sativa; genetic diversity; tidal swamp; breeding and conservation programs

\section{Introduction}

The tidal swamps are a potential area to be developed into future agricultural farming in many Asian countries because still widely available with a total of 20.1 million hectares [1]. While the region considers the limitations as fragile or marginal areas, primarily due to natural problems, it reserves an excessive amount of indigenous rice germplasm [1]. Hundreds of the tidal swamp rice landraces have been found in the region, and show some beneficial agronomic traits. By the result of domestication process and through the natural selection for a long-time, this germplasm shows a better adaptation to the local conditions and cultures [2]. This germplasm also exhibited both a tremendous genetic diversity and the substantial genes in promoting the development of new rice cultivars in the future [3-5].

In South Kalimantan for example, one of the biggest rice producers in Indonesia, there is about 70 tidal swamp rice cultivars which still found and preserved by the local farmers [6]. Nevertheless, most of this germplasm has not adequately understood genetically and not incorporated optimally into the rice breeding programs $[7,8]$. In general, characterization of rice germplasm has been undertaken based on a morphological marker $[9,10]$. However, this marker has some disadvantages, such as time-consuming, unreliable in discriminating species with closely related taxa [10], and strongly influenced by the environmental factors [11].

The molecular marker application may contribute in-depth information on the potential and genetic diversity of the rice germplasm [12]. This marker has more effective, efficient and accurate, and stable to environmental changes than morphological marker [11]. DNA sequencing is a part of 
molecular applications that constitute a substantial contribution to the study of phylogenetic, whether in plants with distant or close relationships [13,14]. In this case, the chloroplast trnL-F genes and nuclear intergenic spacer (IGS) region sequences could be used for that purpose $[15,16]$. It is because both have an elevated mutation rate, as well as the genetic diversity [17-20]. Some of the plant germplasm have revealed by these markers, like Brassica [21], Oryza [14,22], tomato [23], and Annonaceae [24].

This study directed to investigate and determine the genetic diversity and relationship of the tidal swamp rice germplasm of the South Kalimantan Province, Indonesia using the chloroplast trnL-F and nuclear IGS sequences. In a local scale, such studies could reveal the complex interaction between germplasm and farmers cultivation practices in good view [25]. Hence, the results of this study expected to be used as a reference in the rice genetic improvement and conservation program in the future.

\section{Materials and Methods}

\subsection{Plant Materials}

A total of sixteen cultivars of the tidal swamp rice germplasm, consisting of fifteen of the South Kalimantan Province and one of Sumatera Island, Indonesia (an outgroup) sampled for this study (Table 1, Figure 1). An outgroup cultivar obtained from The Indonesian Agriculture of The Tidal Swamp Research Institute, South Kalimantan, Indonesia. The seeds germinated after being soaked in a fungicide solution and rinsed thoroughly in warm water $\left(30-35^{\circ} \mathrm{C}\right)$. Three-week-old seedlings transplanted into pots with soil collected from a paddy field. The pots were $30 \mathrm{~cm}$ in diameter and 20 $\mathrm{cm}$ in height and placed in a greenhouse. For further analyses, one seedling from each cultivar used.

Table 1. List of the tidal swamp rice germplasm employed in this study.

\begin{tabular}{|c|c|c|c|c|}
\hline Name of cultivars & Genetic status & Grain type & Sub-Species & Origin \\
\hline Adil Ganal & Landrace & Non-glutinous & Javanica & Banjar, South Kalimantan \\
\hline Banih Putih & Landrace & Non-glutinous & Javanica & Banjar, South Kalimantan \\
\hline Bayar Papuyu & Landrace & Non-glutinous & Close to Japonica & Banjar, South Kalimantan \\
\hline Bayar Putih & Landrace & Non-glutinous & Javanica & Banjar, South Kalimantan \\
\hline Ciherang & Improved & Non-glutinous & Javanica & $\begin{array}{c}\text { Tanah Laut, South } \\
\text { Kalimantan }\end{array}$ \\
\hline Ganal Perak & Landrace & Non-glutinous & Javanica & Banjar, South Kalimantan \\
\hline Lakatan Siam & Landrace & Glutinous & Javanica & Banjar, South Kalimantan \\
\hline Lakatan Pacar & Landrace & Glutinous & Javanica & $\begin{array}{c}\text { Barito Kuala, South } \\
\text { Kalimantan }\end{array}$ \\
\hline Lakatan Wangi & Landrace & Glutinous & Javanica & Banjar, South Kalimantan \\
\hline Pandak Laut & Landrace & Non-glutinous & Intermediate & Banjar, South Kalimantan \\
\hline Pandak Putih & Landrace & Non-glutinous & Javanica & Banjar, South Kalimantan \\
\hline Siam Babirik & Landrace & Non-glutinous & Intermediate & $\begin{array}{c}\text { Tanah Laut, South } \\
\text { Kalimantan }\end{array}$ \\
\hline Siam Kuning & Landrace & Non-glutinous & Javanica & $\begin{array}{l}\text { Tanah Laut, South } \\
\text { Kalimantan }\end{array}$ \\
\hline Siam Mutiara & Landrace & Non-glutinous & Indica & $\begin{array}{c}\text { Barito Kuala, South } \\
\text { Kalimantan }\end{array}$ \\
\hline Siam Oon & Landrace & Non-glutinous & Indica & Banjar, South Kalimantan \\
\hline Sardani $^{1}$ & Landrace & Non-glutinous & Close to Indica & Sumatera Island \\
\hline
\end{tabular}




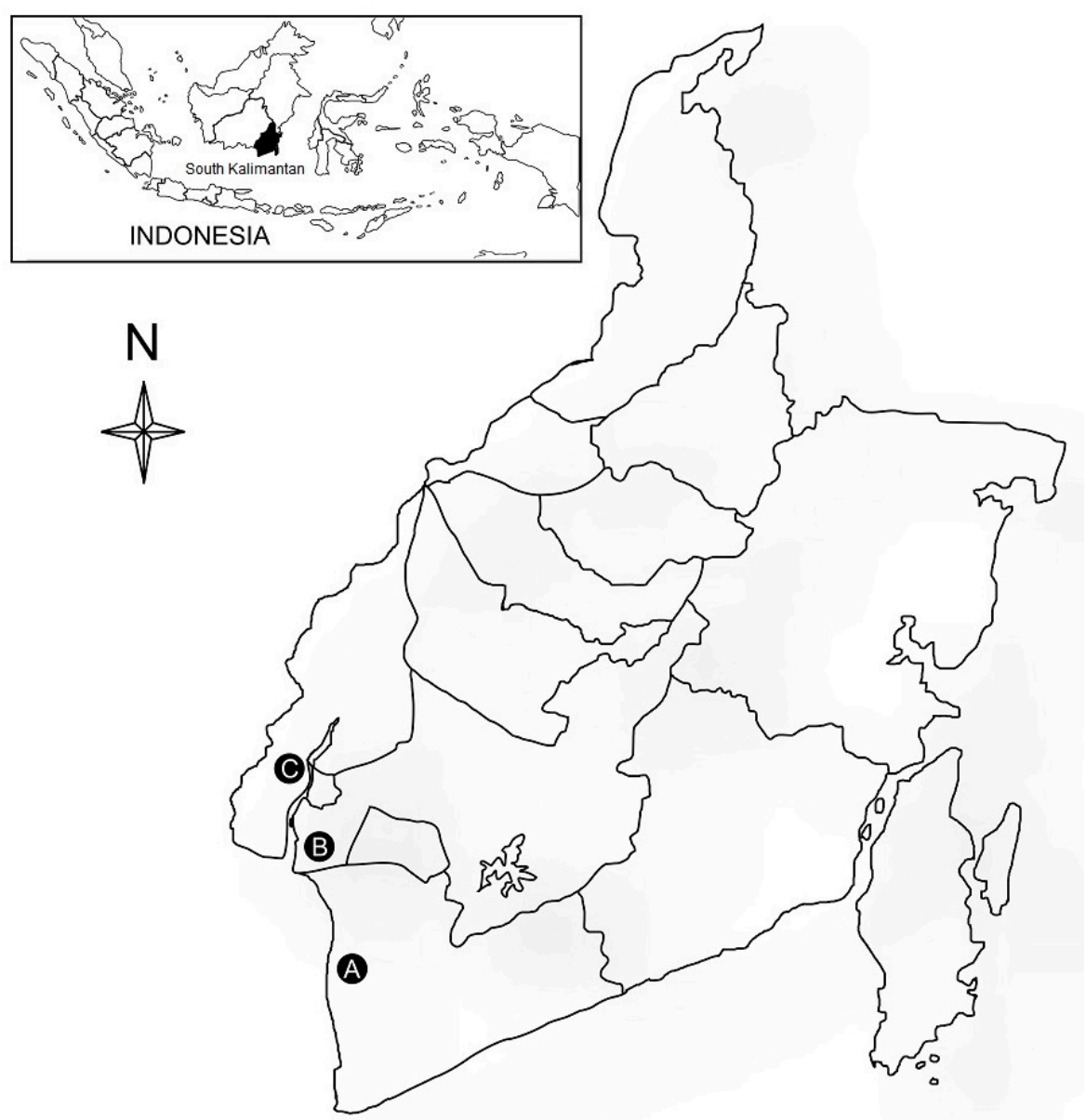

Figure 1. A map of Indonesia showing three collecting sites of the tidal swamp rice germplasm in the South Kalimantan Province, Indonesia: Tanah Laut (A), Banjar (B), and Barito Kuala (C).

\subsection{DNA isolation, amplification, and sequencing}

Isolation of genomic DNA using three-weeks-old of each rice leaf sample, following the Mini Kit of DNA Extraction protocol (Geneid, UK). The genomic DNA isolated then measured using UV-VIS spectrophotometer (NanoVue, GE Healthcare, UK), at wavelengths of $260 \mathrm{~nm}$ and $280 \mathrm{~nm}$ [26]. The isolated DNA samples were then amplified using the chloroplast $\operatorname{trn} \mathrm{L}-\mathrm{F}$ and nuclear IGS primers (Table 2). The reaction was carried out at a total volume of $25 \mu \mathrm{L}$, consisted of $1.25 \mu \mathrm{l}$ of 10 ng DNA template, $4.75 \mu \mathrm{l}$ of the PCR grade water, $1.25 \mu \mathrm{l}$ each primer $(0.5 \mu \mathrm{M})$, and $16.50 \mu \mathrm{l}$ master mix PCR (Kapabiosystem). The master mix PCR containing $50 \mathrm{mmol} \mathrm{KCl,} 10 \mathrm{mmol}$ Tris-HCl pH 8.8, $0.1 \%$ Triton-X, $1.5 \mathrm{mmol} \mathrm{MgCl} 2,200 \mu \mathrm{mol} \mathrm{dNTP}$, and 0, $5 \mathrm{U}$ Taq DNA polymerase. All amplification performed in a Thermal Cycler PCR (Biorad T100, USA) by 35 cycles, and programmed with the following conditions [14]: (1) An initial denaturation for 3 min at $95^{\circ} \mathrm{C}$; (2) Denaturation for $30 \mathrm{sec}$ at $95^{\circ} \mathrm{C}$, (3) Annealing for $30 \mathrm{sec}$ at $55^{\circ} \mathrm{C}$ for $\operatorname{trn} \mathrm{L}-\mathrm{F}$ and $53^{\circ} \mathrm{C}$ for IGS; (4) Extension for $1 \mathrm{~min}$ at $72^{\circ} \mathrm{C}$; and (5) The final extension for $5 \mathrm{~min}$ at $72{ }^{\circ} \mathrm{C}$. PCR products separated on $1.5 \%$ agarose gels. The amplified DNA fragments which corresponding to the expected size then collected from the gels, purified and sequenced by Integrated DNA Technologies, Singapore.

Table 2. Primers used for PCR amplification and for cycle sequencing.

\begin{tabular}{cccc}
\hline Region & $\begin{array}{c}\text { Forward primer } \\
\left(5^{\prime} \text { to } 3^{\prime}\right)\end{array}$ & $\begin{array}{c}\text { Reverse primer } \\
\left(5^{\prime} \text { to } \mathbf{3}^{\prime}\right)\end{array}$ & Reference \\
\hline trnL-F & CGAAATCGGTAGACGCTACG & ATTTGAACTGGTGACACGAG & Taberlet et al. [20] \\
IGS & TAGGCCTCTCTAAGTCCGCT & GTCCAAAGCAGCTCATACGC & Cordesse et al. [33] \\
\hline
\end{tabular}




\subsection{Data Analysis}

The DNA sequences from the two datasets were separately aligned using the Clustal $\mathrm{X}$ version 2.0 [27] and refined manually. Indels (insertion or deletion) introduced into the alignment coded in the following ways. Shared indels treated as single characters. Indels of uniform length coded as absence (1) or presence (0) characters independent of the indel length. The gapped regions in the alignment excluded from subsequent analysis unless some position included nucleotide diversity. Gaps treated as missing entries [28]. Maximum Likelihood (ML) analysis performed by heuristic search with Nearest-Neighbor-Interchange (NNI) options, strong branch swap filter, and initial tree automatically (Maximum Parsimony). The sequence data were also analyzed with a neighbor-joining method using the Kimura 2-parameter distance estimates [29]. Topological robustness assessed by bootstrap analysis with 1000 replicates using simple taxon addition [30]. The characters weighted equally in all phylogenetic analyses. The phylogenetic analyses conducted by a software of MEGA7 [31].

\section{Results}

\subsection{Sequence characteristics and the genetic diversity}

Approximately 0.89 kilobase pairs $(\mathrm{kb})$ of two sets of DNA fragments from the chloroplast $\operatorname{trn} \mathrm{L}-\mathrm{F}$ and nuclear IGS genomes sequenced separately from sixteen of the tidal swamp rice germplasm. The phylogenetic information generated by both sequences given in Table 3. In general, the aligned sequences of nuclear IGS indicate a more extraordinary value of the number of segregating sites, Bayesian Information Criterion (BIC), and Akaike Information Criterion (AICc) than chloroplast trnL-F. Similarly, GC content and nucleotide diversity were higher in IGS sequences than the chloroplast trnL-F. However, both sequences have a similar value of Ti/Tv ratio (1.13) (see Table 3). Moreover, the Tajima's test of neutrality shows that these sequences have a progressive value of $\mathrm{D}$ greater than zero $(\mathrm{D}>0)$.

Table 3. Comparison of phylogenetic information for the tidal swamp rice genome from two datasets ${ }^{1}$.

\begin{tabular}{cccc}
\hline Parameter & $\begin{array}{c}\text { Chloroplast } \\
\text { trnL-F }\end{array}$ & Nuclear IGS & Combined \\
\hline Range of sequence length $(\mathrm{bp})$ & $936-953$ & $849-1405$ & $1796-2352$ \\
Total number of sites $(n)$ & 936 & 849 & 1780 \\
Number of segregating sites $(S)$ & 929 & 845 & 266 \\
Parameters & 30 & 30 & 30 \\
Bayesian Information Criterion (BIC) & 20221.72 & 29081.93 & 60694.01 \\
Akaike Information Criterion (AICc) & 19993.42 & 28856.57 & 60446.29 \\
Maximum Likelihood Value (lnL) & -9966.65 & -14398.22 & -30193.11 \\
Transition/Transversion Bias Value $(R)$ & 0.58 & 0.56 & 0.68 \\
Ti/Tv ratio & 1.13 & 1.13 & 0.89 \\
GC content $(\%)$ & 35.71 & 69.10 & 51.60 \\
Nucleotide diversity $(\pi)$ & 0.58 & 0.61 & 0.04 \\
Tajima's test of neutrality $(D)$ & 4.12 & 4.57 & -0.54 \\
\hline
\end{tabular}

${ }^{1}$ Based on Kimura 2-parameter Model.

\subsection{Phylogenetic relationship based on the chloroplast trnL-F spacer}

The phylogenetic tree was obtained for the chloroplast $t r n \mathrm{~L}-\mathrm{F}$ sequences from the tidal swamp rice germplasm (Figure 2). In general, four separate groups with relatively high values of bootstrap support (bs) formed on this tree. Based on this tree, the Lakatan Pacar was closely related to Sardani, an outgroup, with a bootstrap value of $100 \%$. Similarly, the Pandak Laut was closely related to Ciherang, an improved cultivar, at $\mathrm{bs}=68 \%$. However, the Sardani has far related to Pandak Putih (bs=99\%). 


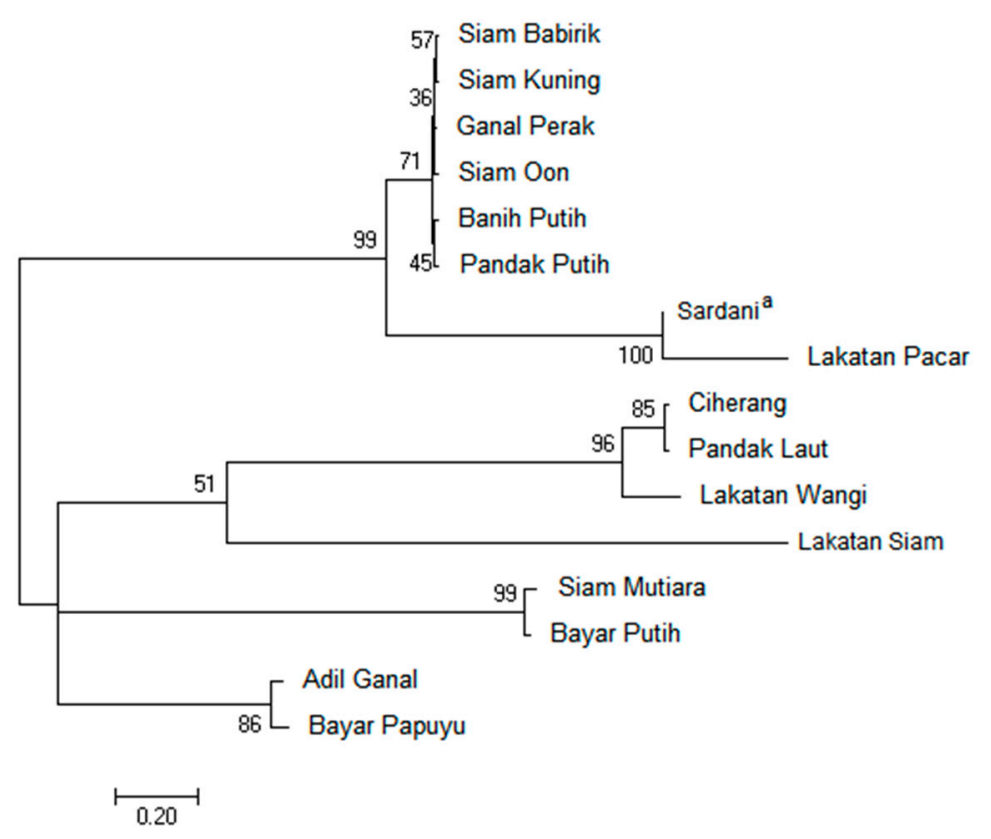

Figure 2. Phylogenetic tree of the tidal swamp rice germplasm based on the chloroplast trnL-F sequences. The numbers above branches indicate bootstrap values inferred from 1000 replicates ( ${ }^{a}$ an outgroup).

\subsection{Phylogenetic relationship based on the nuclear IGS region}

The phylogenetic relationship obtained for the IGS sequences from the tidal swamp rice germplasm. The IGS tree shown in Figure 3. In general, two independent groups of the tidal swamp rice germplasm resolved by the IGS sequences. Differ from the trnL-F, the IGS was able to combine the Sardani with three tidal swamp rice germplasms of the South Kalimantan, such as Lakatan Pacar, Banih Putih, and Ganal Perak, at a bootstrap value of $96 \%$. Whereas, the Ciherang clustered with Pandak Putih, not with Pandak Laut, in a similar group (bs=100\%) as well. In this tree, the far related showed by Lakatan Pacar and Sardani.

\subsection{Phylogenetic relationship of combined chloroplast and nuclear datasets}

One most phylogenetic tree reconstructed based on the combined of two individual sequencing datasets (Figure 4). This combined dataset produced many changes in a phylogenetic tree of the tidal swamp rice germplasm, including their bootstrap values. In general, two independent groups formed on this tree, and relatively similar to the topology of the IGS phylogenetic tree. In this case, Lakatan Pacar has closely related to Sardani at $100 \%$ bootstrap support, whereas Ciherang to Lakatan Wangi and Pandak Laut (bs=100\%). Based on this tree, Sardani and Ganal Perak were two cultivars with considering the farthest relationship. 


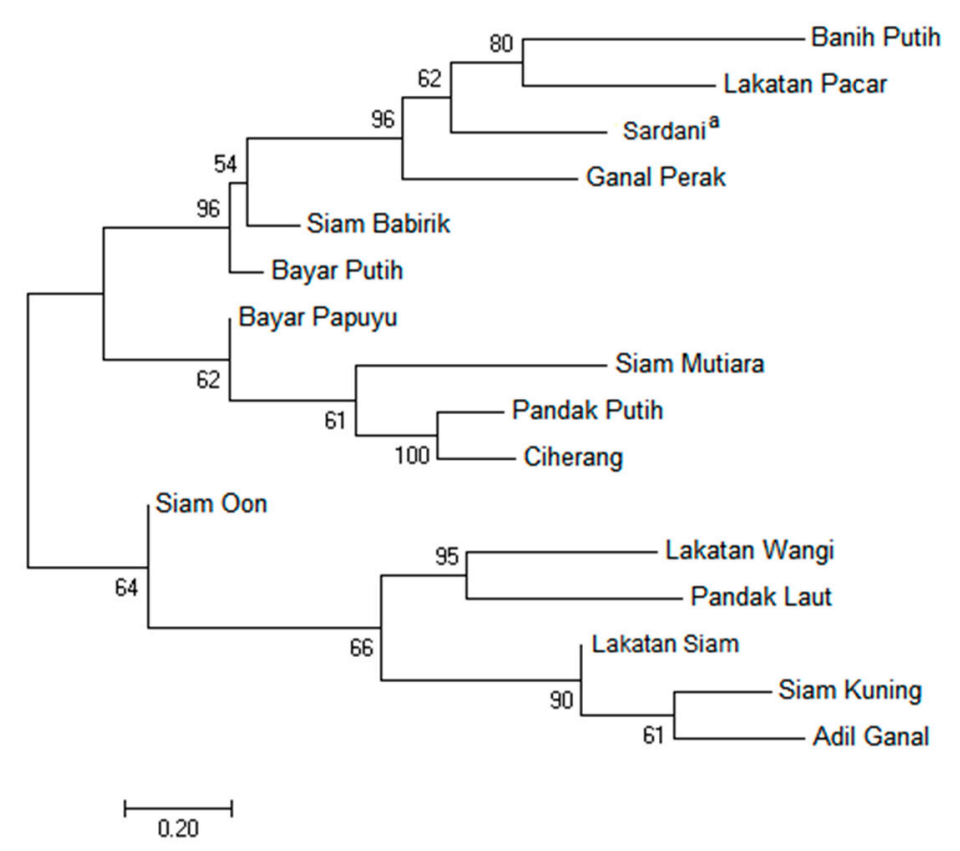

Figure 3. Phylogenetic tree of the tidal swamp rice germplasm based on the nuclear IGS sequences. The numbers above branches indicate bootstrap values inferred from 1000 replicates (a an outgroup).

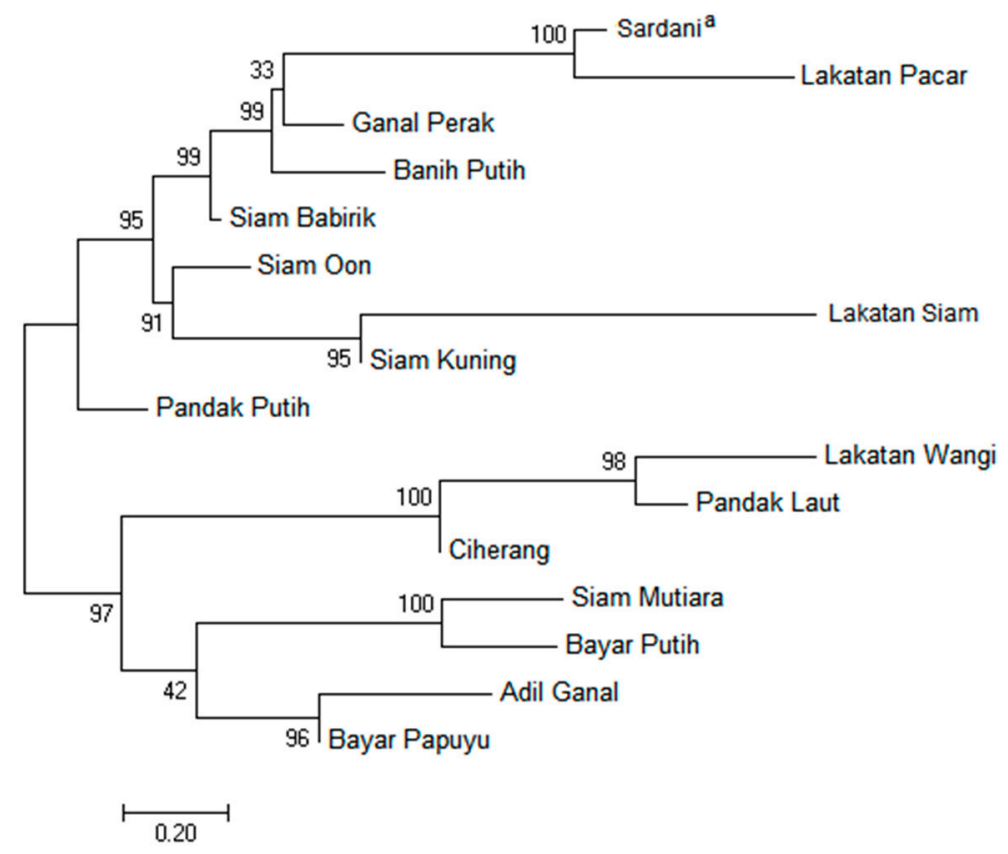

Figure 4. Phylogenetic tree of the tidal swamp rice germplasm inferred from the combined of chloroplast trnL-F and nuclear IGS sequences. The numbers above branches indicate bootstrap values inferred from 1000 replicates ( ${ }^{a}$ an outgroup).

\section{Discussion}

Genetic diversity manifested by differences in many characters, such as morphology, anatomy, and in the proteins, enzymes and DNA sequences of almost all organisms [32]. It required for populations to adapt the environmental changes [32]. In our results, the aligned sequences of nuclear IGS show a relatively higher genetic diversity than chloroplast $t r n \mathrm{~L}-\mathrm{F}$, indicated both by nucleotide diversity and the number of segregating sites (Table 1). Moreover, this region strongly influenced by some mutations, like deletion and substitution, as reported by Cordesse et al. [33]. In the Oryza genus, the IGS shows a high genetic diversity as well [33]. According to Chung et al. [34], nuclear 
IGS have been changing quickly, both in the number of copies and its chromosome segments. Furthermore, Chung et al. [34] reported that this region on some chromosomes of 10 genera of Oryza has an excessive number of repeated elements, located at the end of the short arm of chromosome 9 [34].

Based on the result, while the chloroplast trnL-F has relatively lower genetic diversity than IGS, it could be useful for phylogenetic studies [20]. Drábková et al. [35] reported that trnL-F has a higher substitution rate than an insertion-deletion (indel), making it a valuable tool for studying short-term evolutionary processes. Furthermore, Bayer and Starr [36] confirmed that this region is a primary tool for phylogenetic studies because of mutation rates of insertion-deletion. Thus, both sequences (trnL-F and IGS) have a good chance to apply in the future rice breeding program or developing new rice cultivars.

Overall, the tidal swamp rice of the South Kalimantan, Indonesia demonstrated a relatively more extraordinary genetic diversity than other local rice germplasm. For instance, in this study, our rice germplasm showed a genetic diversity by 0.61 for nuclear IGS and 0.58 for $\operatorname{trn} \mathrm{L}-\mathrm{F}$, whereas the Bangladesh local rice, using SSR markers, only had 0.46-0.53, as reported by Wang et al. [37]. Similarly, using SSR markers, the South Korean local rice showed a lower genetic diversity $(0.035)$ than our studied rice [22]. Thus, this indicates that the tidal swamp rice germplasm experienced a long-term period of domestication process [38]. In fact, this process may generate the changes of an individual genome [39]. Furthermore, the Tajima test of neutrality indicated that selection balance (there are no rare alleles) has occurred in this rice population [40]. Thus, the more accurate application of other molecular markers, such as single nucleotide polymorphism (SNP), to study the local rice population is profoundly important to do.

Further, studies on phylogenetic relationships are indispensable to support the rice breeding programs in the future [41], particularly in choosing the parents for developing new rice cultivars. These studies are extensively conducted by many researchers, such as Kim et al. [22], Choudhury et al. [42], Liu et al. [11], Zhang et al. [43], etc., using different molecular markers, both in a local and a global scale. Nevertheless, such studies are still limited to the tidal swamp rice germplasm.

Our results revealed the phylogenetic relationships of the tidal swamp rice germplasm of the South Kalimantan, Indonesia based on the chloroplast trnL-F and nuclear IGS sequences. Both reflected the differences in clustering when analyzed separately, four groups for trnL-F (Figure 2) and two for IGS (Figure 3). While these trees have generated by two aligned sequences, both have a low resolution, indicated by the average of bootstrap values for each tree. Such condition can be caused by the weakness of sequence variation used [14]. For this reason, Anderberg et al. [44] suggested the combined sequence data use in increasing the phylogenetic tree resolution.

In this study, the combined sequences of both regions provided a better resolution of a phylogenetic tree than sequence data used separately (Figure 4) but generated a similar pattern of a tree by IGS. This tree, however, could not show the germplasm groupings based on the geographical origin as well. Using the combined sequences data of chloroplast tr $r \mathrm{~L}-\mathrm{F}$, nuclear ITS, and mitochondrial nad1 of the Oryza genus, Duan et al. [14] reported a different result of this study, where the phylogenetic tree has a high-resolution with a geographical origin associated.

Regardless of there is no association of geographical origin, the phylogenetic trees provided a unique illustration, where rice germplasm has a monophyletic divergence (derived from a common ancestor). Using the chloroplast tr $n \mathrm{~L}-\mathrm{F}$ sequences, Hall et al. [45] succeeded to show and reconstruct the genetic relationships of Capparaceae and Brassicaceae and concluded that their genetic divergences are monophyletic. Such cases are also reported on Diseae (Orchidoideae: Orchidaceae) [46]. However, in Annonaceae, Pirie et al. [24] revealed a different phylogenetic signal to this marker. According to Pirie et al. [24] this probably due to the genes paralogy, caused by duplicating events, in the past, where the second copy of trnL-F diverged from the first trnL-F directly from Annonaceae ancestor.

Using the chloroplasts and nuclear genome on clustering, Kim et al. [22] succeeded to classify and reconstruct the phylogenetic relationships of nine species of Oryza into three different groups. The same grouping is also shown by Duan et al. [14] when analyzing the Oryza genus using a combined sequence data of chloroplast tr $n \mathrm{~L}-\mathrm{F}$ and nuclear ITS, as well as mitochondrial nad1. Thus, 
the markers can be used in other phylogenetic studies [47]. Whereas, this result may provide a particular opportunity to explore phylogenetic relationships of the tidal swamp rice germplasm from different angles in the future.

\section{Conclussion}

The tidal swamp rice of the South Kalimantan, Indonesia demonstrated a relatively more extraordinary genetic diversity than other local rice germplasm. In this study, this germplasm showed a genetic diversity of 0.61 for nuclear IGS and 0.58 for trnL-F. The phylogenetic reconstruction also exhibited that this germplasm has the unique illustration of phylogenetic trees, particularly for the combined sequences datasets. Thus, the results of our study would provide useful information for further understanding of evolutionary relationships of this germplasm and facilitate the efficient utilization of valuable genes for genetic improvement, particularly in the tidal swamp areas.

Acknowledgments: We thank the Director of Indonesian Swampland Agriculture Research Institute (South Kalimantan, Indonesia) for providing Sardani (an outgroup cultivar) for this study. This study was funded by The Ministry of Research, Technology and Higher Education of the Republic of Indonesia (Grant no. 061/SP2H/LT/DRPM/2018).

Author Contributions: DHM, P, IS, and BSD conceived and designed the experiments; DHM and BSD did the fieldwork; DHM performed the experiments; DHM and BSD analyzed the data; IS, P and BSD contributed materials; and DHM and BSD wrote the paper.

Conflicts of Interest: The authors declare no conflicts of interest. The funding sponsor had no role in the design of the experiments, in the collection, analysis, or interpretation of data; in the writing of the manuscript; nor in the decision to publish the results.

\section{References}

1. Sinaga, P. H.; Trikoesoemaningtyas; Sopandie, D.; Aswidinnoor, H. Screening of rice genotypes and evaluation of their ratooning ability in tidal swamp area. Asian J. Agric. Res. 2014, 8, 218-233, doi:10.3923/ajar.2014.218.233.

2. Ray, A.; Deb, D.; Ray, R.; Chattopadhayay, B. Phenotypic characters of rice landraces reveal independent lineages of short-grain aromatic indica rice. AoB PLANTS 2013, 5, 1-9, doi:10.1093/aobpla/plt032.

3. Chakravorty, A.; Ghosh, P. D.; Sahu, P. K. Multivariate analysis of phenotypic diversity of landraces of rice of West Bengal. Amer. J. Exp. Agric. 2013, 3, 110-123.

4. Divya, K. Study of genetic diversity in Karnataka rice (Oryza Sativa) landraces using trait specific simple sequence repeat (SSR) markers. Int. J. Thesis Proj. Diss. 2013, 1, 45-70.

5. Das, B.; Sengupta, S.; Parida, S. K.; Roy, B.; Ghosh, M.; Prasad, M.; Ghose, T. K. Genetic diversity and population structure of rice landraces from Eastern and North Eastern States of India. BMC Genet. 2013, 14, 1-14, doi:10.1186/1471-2156-14-71.

6. Mursyidin, D. H.; Nazari, Y. A.; Daryono, B. S. Tidal swamp rice cultivars of South Kalimantan Province, Indonesia: A case study of diversity and local culture. Biodiversitas. 2017, 18, 427-432, doi:10.13057/biodiv/d180156.

7. Thomson, M. J.; Septiningsih, E. M.; Suwardjo, F.; Santoso, T. J.; Silitonga, T. S.; McCouch, S. R. Genetic diversity analysis of traditional and improved Indonesian rice (Oryza sativa L.) germplasm using microsatellite markers. Theor. Appl. Genet. 2007, 114, 559-568, doi:10.1007/s00122-006-0457-1.

8. Parikh, M.; Sharma, B.; Chaudhari, P. R.; Bhandarkar, S.; Sharma, D. Collection and conservation of extinct land races of rice from Raigarh district of Chhattisgarh. Recent Res. Sci. Technol. 2014, 6, 111-112.

9. Semwal, D. P.; Pandey, A.; Bhandari, D. C.; Dhariwal, O. P.; Sharma, S. K. Variability study in seed morphology and uses of indigenous rice landraces (Oryza sativa L.) collected from West Bengal, India. Aus. J. Crop Sci. 2014, 8, 460-467.

10. Anumalla, M.; Roychowdhury, R.; Geda, C. K.; Mazid, M.; Rathoure, A. K. Utilization of plant genetic resources and diversity analysis tools for sustainable crop improvement with special emphasis on rice. Int. J. Adv. Res. 2015, 3, 1155-1175.

11. Liu, P.; Cai, X. X.; Lu, B. R. Single-seeded InDel fingerprints in rice: An effective tool for indica-japonica rice classification and evolutionary studies. J. Syst. Evol. 2012, 50, 1-11, 
doi:10.1111/j.1759-6831.2011.00173.x.

12. Pervaiz, Z. H.; Ashiq Rabbani, M.; Khaliq, I.; Pearce, S. R.; Malik, S. A. Genetic diversity associated with agronomic traits using microsatellite markers in Pakistani rice landraces. Electron. J. Biotechnol. 2010, 13, 1-12, doi:10.2225/vol13-issue3-fulltext-5.

13. Soltis, E. D.; Soltis, P. S. Contributions of plant molecular systematics to studies of molecular evolution. Plant Mol. Biol. 2000, 42, 45-75, doi:10.1023/A:1006371803911.

14. Duan, S.; Lu, B.; Li, Z.; Tong, J.; Kong, J.; Yao, W.; Li, S.; Zhu, Y. Phylogenetic analysis of AA-genome Oryza species (Poaceae) based on chloroplast, mitochondrial, and nuclear DNA sequences. Biochem.l Genet. 2007, 45, 113-129, doi:10.1007/s10528-006-9062-x.

15. Baldwin, B. G.; Sanderson, M. J.; Porter, J. M.; Wojciechowski, M. F.; Campbell, C. S.; Donoghue, M. J. The ITS region of nuclear ribosomal DNA - A valuable source of evidence on angiosperm phylogeny. Ann. Missouri Bot. Gard. 1995, 82, 247-277, doi:10.2307/2399880.

16. Soltis, D. E.; Soltis, P. S. Choosing an approach and an appropriate gene for phylogenetic anlysis. In Molecular Systematics of Plants II; 1998; pp. 1-42 ISBN 0412111314.

17. Mort, M. E.; Archibald, J. K.; Randle, C. P.; Levsen, N. D.; Ryan O’Leary, T.; Topalov, K.; Wiegand, C. M.; Crawford, D. J. Inferring phylogeny at low taxonomic levels: Utility of rapidly evolving cpDNA and nuclear ITS loci. Amer. J. Bot. 2007, 94, 173-183, doi:10.3732/ajb.94.2.173.

18. Rogers, S. O.; Bendich, A. J. Ribosomal RNA genes in plants: variability in copy number and in the intergenic spacer. Plant Mol. Biol. 1987, 9, 509-520, doi:10.1007/BF00015882.

19. Poczai, P.; Hyvönen, J. Nuclear ribosomal spacer regions in plant phylogenetics: Problems and prospects. Mol. Biol. Rep. 2010, 37, 1897-1912, doi:10.1007/s11033-009-9630-3.

20. Taberlet, P.; Gielly, L.; G., P.; Bouvet, J.; Pautou, G. Universal primer for amplification of three non-coding regions of chloroplast DNA. Plant Mol. Biol. 1991, 17, 1105-1109.

21. Yang, K.; Robin, A. H. K.; Yi, G. E.; Lee, J.; Chung, M. Y.; Yang, T. J.; Nou, I. S. Diversity and inheritance of intergenic spacer sequences of 45 s ribosomal DNA among accessions of Brassica oleracea L. var. capitata. Int. J. Mol. Sci. 2015, 16, 28783-28799, doi:10.3390/ijms161226125.

22. Kim, H.; Jeong, E. G.; Ahn, S.-N.; Doyle, J.; Singh, N.; Greenberg, A. J.; Won, Y. J.; McCouch, S. R. Nuclear and chloroplast diversity and phenotypic distribution of rice (Oryza sativa L.) germplasm from the democratic people's republic of Korea (DPRK; North Korea). Rice 2014, 7, 1-15, doi:10.1186/s12284-014-0007-4.

23. Jo, S.-H.; Koo, D.-H.; Kim, J. F.; Hur, C.-G.; Lee, S.; Yang, T.; Kwon, S.-Y.; Choi, D. Evolution of ribosomal DNA-derived satellite repeat in tomato genome. BMC Plant Biol. 2009, 9, 1-14, doi:10.1186/1471-2229-9-42.

24. Pirie, M. D.; Vargas, M. P. B.; Botermans, M.; Bakker, F. T.; Chatrou, L. W. Ancient paralogy in the cpDNA trnL-F region in Annonaceae: Implications for plant molecular systematics. Amer. J. Bot. 2007, 94, 1003-1016, doi:10.3732/ajb.94.6.1003.

25. Thomson, M. J.; Polato, N. R.; Prasetiyono, J.; Trijatmiko, K. R.; Silitonga, T. S.; McCouch, S. R. Genetic diversity of isolated populations of Indonesian landraces of rice (Oryza sativa L.) collected in East Kalimantan on the Island of Borneo. Rice 2009, 2, 80-92, doi:10.1007/s12284-009-9023-1.

26. Sambrook, J.; Fritsch, E. F.; Maniatis, T. Molecular Cloning: A Laboratory Manual. Cold Spring Harbor laboratory press; 1989; ISBN 13: 978-0879693091.

27. Larkin, M. A.; Blackshields, G.; Brown, N. P.; Chenna, R.; Mcgettigan, P. A.; McWilliam, H.; Valentin, F.; Wallace, I. M.; Wilm, A.; Lopez, R.; Thompson, J. D.; Gibson, T. J.; Higgins, D. G. Clustal W and Clustal X version 2.0. Bioinformatics 2007, 23, 2947-2948, doi:10.1093/bioinformatics/btm404.

28. Petersen, G.; Seberg, O. Molecular evolution and phylogenetic application of DMC1. Mol. Phylogenet. Evol. 2002, 22, 43-50, doi:10.1006/mpev.2001.1011.

29. Kimura, M. A simple method for estimating evolutionary rates of base substitutions through comparative studies of nucleotide-sequences. J. Mol. Evol. 1980, 16, 111-120, doi:10.1007/bf01731581.

30. Felsenstein, J. Confidence-Limits on phylogenies - an approach using the bootstrap. Evolution 1985, 39, 783-791, doi:Doi 10.2307/2408678.

31. Kumar, S.; Stecher, G.; Tamura, K. MEGA7: Molecular Evolutionary Genetics Analysis Version 7.0 for Bigger Data sets. Mol. Biol. Evol. 2016, 33, 1870-1874, doi:https://doi.org/10.1093/molbev/msw054.

32. Frankham, R.; Ballou, J. D.; Briscoe, D. A. A Primer of Conservation Genetics; Cambridge University Press: New York, 2004; Vol. 39; ISBN 0521538270.

33. Cordesse, F.; Cooke, R.; Tremousaygue, D.; Grellet, F.; Delseny, M. Fine structure and evolution of the rDNA intergenic spacer in rice and other cereals. J. Mol. Evol. 1993, 36, 369-379, doi:10.1007/BF00182184.

34. Chung, M. C.; Lee, Y. I.; Cheng, Y. Y.; Chou, Y. J.; Lu, C. F. Chromosomal polymorphism of ribosomal genes in the genus Oryza. Theor. Appl. Genet. 2008, 116, 745-753, doi:10.1007/s00122-007-0705-z. 
35. Drábková, L.; Kirschner, J.; Vlcek, C.; Paces, V. TrnL- trnF intergenic spacer and trnL intron define major clades within Luzula and Juncus (Juncaceae): importance of structural mutations. J. Mol. Evol. 2004, 59, 1-10, doi:10.1007/s00239-004-2598-7.

36. Bayer, R.; Starr, J. Tribal phylogeny of the Asteraceae based on two non-coding chloroplast sequences, the trnL intron and trnL/trnF intergenic spacer. Ann. Missouri Bot. Gard. 1998, 85, 242-256, doi:10.2307/2992008.

37. Wang, M.; Zhu, Z.; Tan, L.; Liu, F.; Fu, Y.; Sun, C.; Cai, H. Complexity of indica-japonica varietal differentiation in Bangladesh rice landraces revealed by microsatellite markers. Breed. Sci. 2013, 63, 22732, doi:10.1270/jsbbs.63.227.

38. Guo, L.; Gao, Z.; Qian, Q. Application of resequencing to rice genomics, functional genomics and evolutionary analysis. Rice 2014, 7, 1-10, doi:10.1186/s12284-014-0004-7.

39. Vaughan, D. A.; Lu, B. R.; Tomooka, N. Was Asian rice (Oryza sativa) domesticated more than once? Rice 2008, 1, 16-24.

40. Tajima, F. Statistical method for testing the neutral mutation hypothesis by DNA polymorphism. Genetics 1989, 123, 585-595, doi:PMC1203831.

41. Chakhonkaen, S.; Pitnjam, K.; Saisuk, W.; Ukoskit, K.; Muangprom, A. Genetic structure of Thai rice and rice accessions obtained from the International Rice Research Institute. Rice 2012, 5, 1-13, doi:10.1186/1939-8433-5-19.

42. Choudhury, D. R.; Singh, N.; Singh, A. K.; Kumar, S.; Srinivasan, K. Analysis of genetic diversity and population structure of rice germplasm from North-Eastern region of India and development of a core germplasm set. PLoS ONE 2014, 9, 1-13, doi:10.1371/journal.pone.0113094.

43. Zhang, T.; Hu, S.; Zhang, G.; Pan, L.; Zhang, X.; Al-Mssallem, I. S.; Yu, J. The organelle genomes of Hassawi rice (Oryza sativa L.) and its hybrid in Saudi Arabia: Genome variation, rearrangement, and origins. PLoS ONE 2012, 7, 1-14, doi:10.1371/journal.pone.0042041.

44. Anderberg, A. A.; Rydin, C.; Källersjö, M. Phylogenetic relationships in the order Ericales s.l.: Analyses of molecular data from five genes from the plastid and mitochondrial genomes. Amer. J. Bot. 2002, 89, 677-687, doi:10.3732/ajb.89.4.677.

45. Hall, J. C.; Sytsma, K. J.; Iltis, H. H. Phylogeny of Capparaceae and Brassicaceae based on chloroplast sequence data. Amer. J. Bot. 2002, 89, 1826-1842, doi:10.3732/ajb.89.11.1826.

46. Bellstedt, D. U.; Linder, H. P.; Harley, E. H. Phylogenetic relationships in Disa based on non-coding Trn L-Trn F chloroplast sequences : Evidence of numerous repeat region. Amer. J. Bot. 2001, 88, 2088-2100.

47. Wambugu, P. W.; Brozynska, M.; Furtado, A.; Waters, D. L.; Henry, R. J. Relationships of wild and domesticated rices (Oryza AA genome species) based upon whole chloroplast genome sequences. Sci. Rep. 2015, 5, 1-9, doi:10.1038/srep13957. 